\title{
Perceptions and Attitudes of EFL teachers towards Inclusion of Kids with Autism in the English Classrooms
}

\author{
Iris Alfi-Shabtay*, Iris Bendavid \\ Levinsky College of Education
}

*Corresponding Author: Iris Alfi-Shabtay, Levinsky College of Education, Israel

\begin{abstract}
This study focuses on 11 English-as-a-foreign-language teachers (EFL) who cope with inclusion of autistic kids in the regular classroom, and inquires their capability to deal with the challenge. An original semi-constructed oral interview is used as a database to map out central themes regarding the perceptions and attitudes of the teachers towards inclusion. Content analysis reveals six major themes: differences, difficulties, strengths, help, self-reduction of the teacher, and exiting of the autistic pupil. Their examination shows that inclusion is important to the teachers, who all believe that kids with autism can and should learn English in the regular class. However, positive attitudes are not enough, as teachers desperately ask for professional training and emotional support. This conflict between teachers' motivation to include as opposed to the limited knowledge, provided by the system, arose a taboo topic, which has hardly been dealt with before. The relevance of the study is highlighted by the current tendency to increase inclusion of kids with special needs in regular classes. The study reveals how this is done without sufficient tools for teachers. The results shed light on this conflict, and may help teachers receive appropriate guidance to successfully face with the emotional efforts involved in inclusion.
\end{abstract}

Key words: autism, kids with special needs, inclusion, EFL, English classroom

\section{BACKGROUND}

This topic of Autism has gained relevance in the last decade (Dromi, 2018), as one in fifty-nine children is diagnosed with Autism, according to the Center for Disease Control and Prevention (CDC). Up until 1988, there was no inclusion of kids with special needs in the regular educational system, and they usually studied in special schools (Avisar, 2015; Egel \&Meleechi, 2007). However, in 1988, the law of Inclusion, which emphasizes the need to include kids with special needs, has been accepted in Israel. Hence, a child with autism will have the right for additional learning and special facilities to make his/her inclusion successful (Reiter \& Sheyin, 2006).

Nevertheless, teachers in regular schools hardly receive any tools to cope with inclusion of autistic pupils, despite the law of Inclusion. The current study therefore requires inclusion in the eyes of educational staff, and questions whether EFL teachers believe that kids with special needs get the maximum of inclusion educationally, socially and mentally. The topic is sensitive and relevant to educational professionals, as well as innovative, as only few have inquired inclusion in a foreignlanguage classroom.

\subsection{Statement Of The Problem}

Autism is a wide developmental disorder, which includes delays and difficulties in social interaction, language, and cognitive, motoric, and sensory difficulties, as well as damage in emotional abilities, behavior and functioning in many different areas (Frith 1997; Dromi, 2018). According to DSM-5, the Diagnostic and Statistics Manual of Mental Disorder, 2013, a delay in general development is expressed in three major domains: a lack in mutual social emotions; a lack in nonverbal communication in order to socially interact, and a lack in developing age-appropriate relationships (American Psychiatric Association, 2013; Pedreno, Pousa, Navarro, Pamias, \&Obiols, 2017).

There are many different signs of autistic behavior in children that range across multiple contexts. Some phenomena involve: extreme social loneliness, disconnection, major language barriers, unusual reactions to others, persistent deficits in social communication and social interaction, persistent impairment in social communication and social interaction, weirdness and restricted, repetitive 
patterns of behavior, interests, or activities, and deficits in social-emotional reciprocity (Ben-Tzvi, 2009; American Psychiatric Association, 2013).Some additional clinical signs of autistic behavior include: pitching and rhythmic thumping of the head, rotating objects, peripheral hugging, and the need to touch everything in sight before sitting down. Regarding language development, repetition of language, repetitive speech or echoed speech and the twisting of pronouns ("I" and "you") are unique characteristics of "autistic language" (American Psychiatric Association, 2013; Bugdashina, 2003; Mazza, Mariano, Peretti, Masedu, Pino\& Valenti, 2017).

Since 2013, there have been some critical changes in the new Diagnostic and Statistical Manual Fifth Edition* (DSM-V) for the analysis of autism spectrum disorder (ASD).One of the most important changes is that the separate diagnostic labels of Autistic Disorder, Asperger's Disorder, and PDD-NOS (pervasive developmental disorder - not otherwise specified) have been put under one umbrella term - "Autism-Spectrum Disorder." The updated diagnosis represents a new, more specific, medical and scientific way of diagnosing people with autism-related disorders. Further differences for ASD will now be made according to severity levels, based on the extent of support needed due to one's challenges. The DSM-V claims the reasons for using the umbrella term of "Autism-Spectrum Disorder" are that the old way is not clear-cut enough, because different doctors determine the same person with different disorders, and some change their diagnosis of the same syndrome from year to year, and also because autism is circled by a common set of behaviors and should be defined by a single name according to severity (American Psychiatric Association, 2013).

The law of special education in Israel, enacted in 1988, came upon to define who a child with special needs is. This law sets the goal of special education: to advance the ability and talents of a special needs-child, to improve his physical ability, his mental ability, and behavior; to widen his knowledge, his skills and to teach one to adapt to acceptable behavior in society, in order to make his inclusion easier wherever he is (Balas \&Adler, 2004). The law has changed over the years, and defined once again the goals of inclusion of the special education, and focused on the needs of the special pupil regarding the cognitive and emotional tools, needed to advance in the society. The premise of the law victoriously, changed the perception of the exceptional person in society, and the tags upon the teaching strategies that will advance special educational pupils to be included into the regular school systems. In addition, the updated law deals with the rights of special education pupils who are in need of special teaching strategies. The law strengthens the need for a special inclusion program and strongly commits the professional staff of the board of education to build a special program for these pupils (Gavish \& Shimoni, 2006; Ben-Yehuda \& Leset, 2004; Reiter \& Sheynin, 2006).

Specifically, the law of inclusive education has changed the dichotomous nature of regular- and special education. It supports the education of children with disabilities alongside their non-disabled peers rather than separately. Inclusive education suggests a modification in the social, cultural, curricular and pedagogical life of the school, as well as its tangible organization (Armstrong, 2011; Dyson, Jones \& Kerr, 2011). Hence, disabled children, including autistic children, have a right to conventional placement, not because that is where they can get the best education, but because they cannot be valued equally with their peers or offered equal opportunities, if they are rejected access to what is otherwise a common educational establishment (Dyson, et al., 2011).

Nevertheless, many conditions should be taken into account in order for the full inclusion of autistic pupils in a regular class, in the same setting as their normally developing peers, be successful (Mesibov \& Shea, 1996). For example, the teacher and assistant need to work together and cooperate. They should also trigger the pupil through visual support, and visual media frequently. Another factor is the buddy program, where other regular pupils help the autistic pupils in different ways (Ferraioli \& Harris, 2011; Shavit \& Tal, 2013). Additional factors that may contribute to the success of inclusion are: student motivation, academic behavior, effective learning, the instructor, and the classroom environment are (Meindl, Delgado \& Casey, 2020).

Research has shown that teachers find it easier to handle students having similar conditions in one class rather than having an autistic pupil in addition to coping with a whole class of regular pupils. They report that regular teachers often feel they lack the skills and strategies to deal with inclusion of kids with special needs in a regular class (Padmadewi\&Artini, 2017). The type and severity of the children's disabilities also affects teachers' willingness to accommodate certain students, as teachers express concerns that they will not be able to effectively manage their classroom when having 
students with autism and behavioral disorder in the general education setting (Cassady, 2011). Segall and Campbell (2012) who examined understanding and beliefs of educational experts regarding Autistic Spectrum Disorder (henceforth: ASD), show that while attitudes towards the practice of inclusion for students with ASD may be positive, an array of outcomes related to both student and teacher effect these opinions. They also found that special educational teachers and school psychologists are better trained to cope with inclusion compared to regular teachers.

Another study of teachers and inclusion shows that regular-education classroom teachers see additional personnel support as being important for the successful inclusion of students with different levels of academic ability. They do not consider student effort when making assessments on the levels of assistance, needed for the special student. When regular classroom teachers request additional personnel support, they do so according to the level of ability of the students. The harsher the disability, the more assistance of additional personnel is requested. (McNally, Cole, Waugh, 2001). Hence, regular-classroom teachers often feel they do not have awareness of the different kinds of solutions, needed to support students at different levels of disability. Rather, it may be that teachers are unaware of the curriculum solutions out there for students with different levels of disability or maybe there are not enough resources available (Boujut, Dean, Groudelle\& Cappe, 2016; Crossland \& Dunlap, 2012; Shani \& Regev, 2017).

In closing, educational frameworks for pupils with autism have changed over the years, and yet, inclusion of autistic pupils in the eyes of educational staff is not necessarily positive. Little has been researched to date on the topic of inclusion of kids with autism in the English classroom, although English is considered a valued discipline in Israel (Alfi-Shabtay \& Kotake, 2021). The current study intends to fill this void and inquire attitudes of EFL teachers in Israel towards inclusion of pupils with autism in the English class.

\section{RESEARCH OBJECTIVES}

The two major goals of the study are:

a. To map out central themes regarding the attitudes of the EFL teachers towards inclusion of autistic pupils in the regular education class.

b. To locate possible differences in attitudes towards inclusion between the staff.

\section{Methods AND MATERIALS}

This study maps out central themes of the perception of EFL teachers regarding inclusion of autistic pupils who study in third-grade English classes in the center of Israel. The study is carried out according to qualitative content analysis and thematic analysis approaches, which are part of the qualitative descriptive research paradigms (Bowen, 2006). This approach refers to the study of personal experiences, elicited in the current study via a given qualitative data of an original semiconstructed oral interview. The analysis requires interpretation of the meaning of content conveyed in specific phenomena and enables the researcher to make inferences about the message within the texts (Creswell, 2013). In interviews of the type used in this study, the formulation of the central questions is done in advance, but the sequence of their presentation is not predetermined. There is scope during the interview to add questions according to the context, and sometimes the answers of the interviewee lead to spontaneous questions (Dushnik, Sabar Ben-Yehoshua, 2001).

\subsection{Participants}

This study focused on eleven EFL teachers; all are female in the range of ages 24-52. They all work in elementary schools in the center of Israel from mid-high socioeconomic background; all are English teachers in the regular educational stream. The study focused on 11 third-grade classes. In each of the regular education classes, there are 28-34 kids, including one autistic child, who has his own assistant. The chronological age of the pupils with autism included the regular class is between 8-9 years old.

\subsection{Tools}

The study involved an original semi-open oral interview (Gibton, 2001), of five questions in Hebrew, designed specifically for the purpose of the study by the two researchers. The interview included: 1 question of general knowledge regarding pupils with autism, 1 question which dealt with the inclusion 
of pupils with autism, 1 question on the social aspect, 1 question on the pedagogical aspect of teaching the English language, and 1 question which focused on the emotional aspect. A pilot study was given to one participant to guarantee that the questions were appropriate and well phrased to the population in this study.

\subsection{Data Collection}

First, an interview was constructed for the pilot study and was given to one participant. The interview was then revised by the two authors, based on the response of the participant and the flow of the interview throughout the pilot. Next, an oral interview was conducted individually with each participant by the second authors in a quiet room; each interview took approximately forty-five minutes. All interviews were being audio recorded with participants' permission, and were then transcribed word-by-word, translated into English, and finally - analyzed qualitatively by content and theme type (Bowen, 2006). To preserve anonymity, all identifying information was removed during the transcribing process, and pseudonyms were used to keep all participants' information confidential.

\subsection{Data Analysis}

This study uses qualitative content analysis and thematic analysis (Bowen, 2006) to locate central themes and perceptions towards inclusion, and find possible differences between the EFL teachers. The interview was first coded into thematic categories, and six major themes were then mapped out from the interviews. Data analysis is characterized as a qualitative process of analysis with intuitive elements or characteristics which aims to give meaning, interpretation and generalization to the phenomenon under study (Gibton, 2001). Analysis used in this study is of a process of ordering and structuring of the collected information for its interpretation and understanding of its meanings (Shkedi, 2007). The results of this study are limited to the specific EFL teachers who took part in this study. Future studies may involve a bigger sample of participants.

\section{Presentations Of Findings}

Findings are presented following the two goals of the study. First, mapping out of central themes regarding the attitudes of EFL teachers towards inclusion of autistic pupils in the regular education class, then - possible differences in attitudes towards inclusion between the staff members who took part in the interviews. Findings are supported by relevant authentic examples from the interviews.

\subsection{Central Themes Regarding Inclusion}

Content analysis mapped out six major themes. These are: differences, difficulties, strengths, help, self-reduction of the teacher, and exiting of the autistic pupil and/or the assistant.The following presents each theme located with authentic examples from the interviews and analysis of the theme.

\section{A. Differences}

The first theme is differences.It refers to what the EFL staff said about the differences between a regular kid/pupil and an autistic kid/pupil.

P: "A child with autism is a child that has many difficulties, specifically social difficulty. From the outside, you cannot see any difference between him and others. In speaking, in behavior, and in responding to other pupils and in behavior towards other pupils. Some make weird sounds or do weird movements, like ticks".

Here P., the English teacher, is familiar with some basic facts that an autistic pupil has many difficulties, especially in the social aspect. P. goes on and points out the differences.For example, in the way an autistic speaks and the weird noises an autistic pupil makes sometimes. She also points out that a pupil with autism looks like a regular kid. Those are some of the differences between a regular pupil and an autistic pupil.

The next quote is from $\mathrm{C}$.

C:"Now, in T.'s situation, the only thing that separates him from others is his reactions. He can suddenly react in an unacceptable manner. For example, if something is said in class, he immediately says what's on his mind because that's what he thought about that moment. He doesn't hold himself back. He just spits it out and therefore it can sound weird at times". 
C. points out the difference between a regular pupil and an autistic pupil as well. C. mentions that T. says exactly what he is thinking about and doesn't hold it in. This difference is very noticeable and felt in the regular classroom since "he spits it out and it can sound weird at times".

The third quote is taken from another English teacher, Z.

Z:"A child with autism, in my eyes, is a child who suffers from a wide range of disabilities, difficulties and hardships. It can be a difficulty in expressing oneself regarding emotions, difficulty in the social aspect, and even the sensory aspect. It's a very wide spectrum, not something specific. He is different than the others in a way that his emotional reactions are exaggerated sometimes, and he doesn't always know how to deal with a reaction himself."

Here Z. also adds to the differences between the pupils. Z. says that an autistic pupil is different in the emotional aspect, and that the pupil himself does not know how to handle his own situation. The next quote is taken from the interview of K., who talks about concrete language, abstract language, and cynicism.

K: "Also when you explain something, it has to be explained in a concrete way. It can't be abstract. If it is abstract, you must give an explanation. If you are talking about fables you must explain. You can't use cynicism and sayings like: the whole world is on his shoulders. Because he will see it in a way that the world is literally on these kids shoulders and not what you mean so you have to make sure he understands these expressions."

Here K. explains that an autistic pupil cannot understand language that is abstract or cynical, when a regular pupil does understand. Abstract and cynicism is often used in language, with all ages. Though, $\mathrm{K}$. explains and gives examples to show that with an autistic pupil it cannot be used at all.

The final quote is taken from an interview with Sh. Here she adds the topic of routine. Routine is very important and necessary to autistic pupils in class and in life.

Sh:"Autistic children really like routine and it's important to keep the routine so that there as little changes as possible. They need a permanent schedule and if there is a change, you need to prepare the child in advance, describe the change, and therefore make it easier on him".

Not only is routine needed, but if there is a change in the routine, it must be explained to the autistic pupils in advance, in order to make it easier on them, or else, they can respond in ways that are not acceptable, and makes them stressed.

\section{B. Difficulties}

The second theme is difficulties. This theme is interesting, as it is divided into two: 1.the difficulties of the autistic child, and 2. the difficulties of the regular teacher. The first three quotes are the difficulties of the autistic child.

$P: " T h e$ difficulty was when they would behave in a way that was unordinary like screaming and leaving without permission. The difficulty is in behavior. I remember a specific pupil that I taught in the past, one day it rained hard and the pupil went ballistic. The assistant was not there that day, I didn't know what to do".

P. brings up two difficulties of the autistic pupil. One, in behavior, Two, the assistant was not there. Regarding behavior, the autistic pupil does things that are out of the ordinary, like screaming and leaving without permission. Regarding the assistant, the autistic pupil needs to cope on his own, with certain issues, without the additional support of the assistant. The assistant has one day off every week throughout the year. It does not matter what the schedule is. If there is English on that day then the teacher will teach without the help and support of an assistant. The next quote of C. adds the subject of tiredness to the list of difficulties. The autistic pupils get tired during the English lesson in following the tasks given.

C:"Sometimes he gets tired during the lesson and doesn't want to do all the tasks, so I reduce the number of tasks he needs to do. I whisper in his ear or take him aside and that calms him. I answer his difficulties and his needs because sometimes he asks for help. At the beginning of the year, he expressed that he is tired and he doesn 't need to do everything". 
There are times when the autistic pupil gets tired and has a hard time cooperating. Therefore, the teacher helps out and reduces the tasks, so the autistic pupil will not feel frustrated. She also needs to calm him down. Luckily, in this situation, he shares with the teacher that he is tired, and then she can do her best to guide in.

The last quote concerning difficulties of the autistic pupil is of loneliness. The autistic pupil is alone, especially when the assistant is on her day off.

$Z: " W h e n$ the assistant is not in school, the boy is alone, but a girl sits next to him, she really wants to help, so she helps. And he listens to her".

The next three quotes refer to the difficulties of the teacher. P. speaks about her lack of knowledge on autism.

$P: " I$ never studied about children and autism, so I know only from my teaching experience about the things he needs in class and how to help him".

Since P. never studied the subject of autism, she bases her actions on experience in general and paying attention to the things the pupil needs in class and on how to help him. The next quote brings up lack of time and the difficulties around this topic.

$C:$ :It could be done for sure but I don't because of my own lack of time. Because of the incapability of planning ahead, I just can't get there. But in his case, it's totally right to do".

Here C. talks about her lack of time which reflects on the incapability of planning ahead. Planning ahead is important, but sometimes impossible.The last quote regarding the difficulty of the teacher is that each and every pupil is on his own level in English. Here the teacher says that there are different levels in English just like there are in other subjects. That sums up difficulties of the child and of the teacher from the interviews.

A:"Yes, like any other subject, every pupil is on his own level. There is no difference. There are actually autistic pupils that are very strong in English. They get the language because they get templates and therefore learning the language might be even easier for them then the regular pupils. It's part of their difficulty or their strengths. It's very general, because every pupil is strong and week in all different subjects as well as English".

\section{Strengths}

The third theme is strengths. This theme is also divided into two: 1.the strengths of the autistic child and 2.the strengths of the teacher. The first three quotes are of the strengths of the child.

\section{C:"Study wise he was successful and very smart in English and other subjects".}

The autistic pupil in C.'s class is bright in general, which a major strength. He also does very well in English.

Z:" The autistic child doesn't always talk to the others, he talks to me, but doesn't really use the help of others. I don't see communication with others".

The teacher Z., does not see the autistic pupil talk to the other pupils, but what is a huge strength for this child is that he does communicate with the teacher. P. adds to this and says, that autistic pupils have a great memory and catch on to languages, which is another huge strength.

$P: " I$ believe they need to learn English. They have a great memory and catch on to languages. Regarding the level, he was at the level of the class and even advanced. He enjoyed the lesson. He fits in study wise and especially in English".

Learning EFL is a must for autistic pupils, who are integrated in a regular education classroom, and sometimes they are even better than regular pupils in English. Next are the strengths of the teacher.

C: "But I would really want the pupil to experience success, and I do all that I can to make it happen".

The teacher wants the pupil to succeed and makes a point in saying that she really tries her best to make it happen. She is determined, this is her strength.

Similarly, S. says: 
Perceptions and Attitudes of EFL teachers towards Inclusion of Kids with Autism in the English Classrooms

S.:"I think that we have a good connection. I succeed in understanding them and I understand their difficulties and find solutions most of the time. I try to do my best".

The next quote is from $\mathrm{D}$, who talks about the strength in connecting to the assistant and to people in general.

D:" I have a great connection with the assistants in all aspects, I always have. I think it has

to do with personality. I'm easy going and get along well with most people".

That is surely a strength a teacher can have, getting along and connecting to the assistants and pupils is an important strength.

\title{
D. Help
}

The fourth theme is Help. This theme splits into four: 1.the teacher helps the autistic pupil 2. the assistant helps the teacher 3 . the assistant helps the autistic pupil and the regular pupils 4 . the regular pupils help the autistic pupil. The first quote focuses on when the teacher helps the autistic pupil.

\begin{abstract}
P.:"I never studied about children and autism, so I know only from my teaching experience about the things he needs in class and how to help him...first of all, individual attention is important, so he won't feel different even though he does get special attention. A bit more personal attention from the teacher in order to make sure he is on board regarding studies... In the lesson itself, to include him study wise, and to try to get him to participate in the lesson. To understand part of the lesson, sometimes it works and sometimes it does not.
\end{abstract}

P. mentions individual attention; an autistic pupil needs individual attention from the teacher at times.It is important to study wise so that he will understand, succeed and feel included in the lessons.

The next part focuses on how the assistant helps the teacher. P. says that the assistant's English is not on a high level, but the assistant does help the teacher with photocopying worksheets when needed for the class.

P:"I'm thinking of a specific assistant I worked with in the past, our work together was minimal. Her English was not on a high level. She would leave the class to help me with technical things. But to get advice from her, was not the option. There was nothing urgent in her help. Sometimes she would leave the class to photocopy some worksheets when I asked her to".

There are times when the assistant turns to the teacher to inform her on the autistic pupil's emotional situation. This also can be very helpful. Here S. reports on a case as so.

S.:" Yes, always since sometimes there is difficulty emotionally. So, the assistant is there and helps when needed...mostly yes, when the assistant reports to the teacher on what is going on with the pupil. If we know that the pupil is not doing well emotionally, the assistant tells the teacher. The teacher reports on homework, on changes, on materials she will teach, and in general they help each other".

The third part in the theme of Help is how the assistant helps the autistic pupil and/or the regular pupils.

E.:" The assistant took him swimming with the $2^{\text {nd }}$ graders and the instructor told the kids to do something with a rubber band. They had to try 5 times. They all succeeded but him. She explained to him what to do. He looked up at me and said: what is wrong with me, its' something very simple, why can't I do it? Here we understood that he is starting to understand that he is different".

E. has a high comprehension of what the boy is feeling and going through. E. tries her best to guide the boy and the assistant through the task. E. tries to prove to him that she, too, has certain difficulties.

The last part of help is when a regular pupil helps the autistic pupil during the lesson, and the assistant is not there for that hour or for the whole day. The regular pupil sits near the autistic pupil and gives instructions and guidance.

P: "When the assistant is not present or when the assistant leaves the class, there is a specific pupil that sits next to him and he behaves like an assistant would, and it's amazing. 
Perceptions and Attitudes of EFL teachers towards Inclusion of Kids with Autism in the English Classrooms

The pupil helps the autistic child with instructions and inclusion in the class. It helps, but when there are difficulties it's problematic. I feel helpless, and get stressed out and I ask the inclusion advisor to come and help out".

\section{E. Self-Reduction of the Teacher}

The fifth theme is self-reduction of the English teacher. Z., the English teacher below explains how the regular pupil that sits next to the autistic pupil is a great help; even better of a help than the teacher is at times.

$Z: " N o, I$ have no contact with the inclusion coordinator regarding autistic pupils, and I never received any help from her side. Even so, I do consider the inclusion in my class a success because the boy works very nicely. He participates sometimes, knows where we are in the material, and even shows me his notebook. In general, I see that he gets along, and is included nicely. Mostly it has nothing to do with the assistant, or me and it's specifically because of a girl that sits next to him, a girl that helps him. I dotry to help him and do worry about him; I want him to be with us on the same page, so it's a lot of things together".

P. talks about her emotions; how she feels helpless at times, stressed and reaches out for help from the advisor.

$P: " I t$ helps, but when there are difficulties, it's problematic. I feel helpless, and get stressed out and I ask the inclusion advisor to come and help me out... because of work load, and in life, I really try to do as much as I can. But to say that I shared with her, I never got to it. Though within the lesson, I would talk to her and show her what we are doing on that day. And what he needs to do. That's what I do. Things need to be planned ahead of time. It's important that there is an assistant that wants to work together. I don't see too many assistants like that unfortunately. Ones that are willing to advance the pupil study wise".

P. continues to talks about being over loaded and is really trying her best but it is difficult for her to plan ahead when so much is going on.

Finally, C. repeats many times how she feels that the boy's success has nothing to do wither at all. The repetition emphasizes and strengthens her feeling on this matter.

C:"I didn't run into a situation where pupils didn't succeed study wise. The success is actually from the moment I met him. He is a child that succeeds. That means that his success is not because of me or because of something that happened this year, he is a brilliant boy. I am very happy of course but it has nothing to do with me. The truth is that the autistic pupil in my class hardly disturbs, sometimes he reacts in an unacceptable way but he is a child who knows how to hold himself back. I believe that there is work done with him that has nothing to do with me".

\section{F. Exiting of the Autistic Pupil and/or the Assistant}

The sixth theme is the exiting of the autistic pupil and/or the assistant. Sometimes together and sometimes separately. A. speaks about the exiting of the assistant on purpose so that the autistic pupil can be independent.

A:" It depends on the child. There are times when we ask the assistant to be outside the classroom so that the pupil can practice the tools that he learnt, the assistant is out part of the time. There are also assistants that are undercover; the goal is that they are present when the child practices the tools he learnt.

S. talks about the autistic pupil exiting in order to calm down and to be away from others, so that they will not hurt his feelings.

Sh: "There are situations where they don't behave, and there are situations where they behave perfectly. I try not to turn it into drama, and not to make a big deal, I take him out to calm down and take him away from the others so that kids won't laugh at him or insult him, or look at him in a weird way. And if I have a small group, and I have a chance to explain the situation, or talk about it, I do". 
Overall, the six central themes regarding inclusion indicate that pupils with autism are different.They say what is on their mind, their emotional aspect is different, concrete language cannot be used, and they need routine. The difficulties of the pupil with autism are in behavior, coping when the assistant is not around, and feeling lonely at times. The difficulties of the regular EFL teacher are: lack of knowledge on autism, lack of time for preparing special materials for the kid with special needs, and the different levels of the pupils. Both autistic child and the regular teacher have strengths. There is a big circle of help that is in action between the regular teacher, the pupil with autism, the assistant, and the regular pupils. The EFL teacher does not have enough confidence in her actions, and may feel helpless or overloaded at times. Finally, exiting of the pupil with autism or the assistant have legitimate reasons.

\subsection{Differences in Attitudes}

The second goal was to locate possible differences in attitudes towards inclusion between the staff members who took part in the interviews. Content analysis (Bowen, 2006) shows that the teachers in general believe that inclusion in the EFL classroom is important. Nevertheless, they reveal many difficulties due to lack of knowledge. The quote below is from an EFL teacher who teaches many years in the regular English class and has pupils with autism included in to her lessons. P. brings up the topic of including a pupil with autism in all aspects, depending on what he can handle and to motivate the pupil to be included.

$P:$ "When an autistic pupil is included in all aspects, recess, food time, trips, plays, that is the maximum of inclusion and in which the autistic pupil can handle. It depends on the child and what he can handle. They need to be included socially and not to be included sometimes but all the time.

In the lesson itself, to include him study wise, and to try to get him to participate in the lesson. To understand part of the lesson, sometimes it works and sometimes it does not. It depends on the child's situation. When there are tasks in groups, to include him as well. "

Nevertheless, P. also mentions the problematic situation of inclusion in crowded classes.

"I will tell the truth even though it's sad to hear. Because these days there are so many pupils in a class, I would give up on the inclusion of an autistic pupil. I simply don't get to a fourth of the pupils in class, the quiet pupils. An autistic pupil needs a lot of personal attention and sometimes it's hard on me. You know what, it also depends on the level of the pupil and his difficulties because there are so many different levels. If it's a pupil on a high level, then yes. But from my experience with the assistants, I worked with in the past and the autistic pupils I worked with in the past, I wouldn't want an autistic pupil in my class every single year, unfortunately. Because it takes a lot out of me, a lot of energy and attention, and then I miss out on 5-6 pupils. I just want to remind you that I haven't had an autistic pupil in my class, or any of my classes for years now. By chance."

C., another EFL teacher, brings up the fact that over the years the levels of the pupils with autism is different. In addition, the relationship between the people involved needs to be effective and strong.

C:"From what I know up until now, it really depends. This year I have a pupil like this, and a few years ago I had a pupil where his acclimatization was less successful. I think of a child's personality, I don't really understand autismand children on the spectrum but it often changes, I've never seen something stable. In general, I think it's a good thing and positive but of course we need to check changes and factors. The connection between the assistant and the child, the connection between the parents and the school.

As a professional teacher, I don't really think of it much. I know that as a homeroom teacher, we are always talking about accepting others, acceptance of one who is different; we also talk about helping others and also talking when something is hard for me. When the teacher gives tools to her pupils, and there is inclusion of a pupil in class it comes about. And they learn values. I believe a class should be heterogeneous, it's very important. Children gain from this. They are exposed to things and become more sensitive."

Z.'s interview also brings up the issue of the importance of inclusion in school and in society as a whole. 


\begin{abstract}
Z.: "Inclusion of pupils is a must. We cannot exclude them from the society. We are a society which has everything and as long as we are able to educate inclusion of children with autism, the better it will be. Especially in a school which is so big, where the social message is to understand and accept others that are different, to respect, and to help where needed. This is our message in society and individually. Inclusion in my eyes is when the autistic child feels as normal as the others, not different, and not lonely."
\end{abstract}

$Z$. further talks about the benefits for both sides, the pupil with autism and the regular pupils in class.
Z:"It's hard for me to answer that question because I'm not a homeroom teacher. I don't know. I think the inclusion that is done in school, has good intentions. If there is a class that has dance, so they include the autistic pupils in the lesson and the regular class gets to benefit as well from this. And the autistic pupils gain another lesson. I think the inclusion is good."

Overall, the EFL teachers show similar perspectives towards inclusion, and believe that it needs to be in all aspects. All see benefits to inclusion, and say the pupils with autism need to be an integrated part of society. The teachers agree that there must be a school-plan for each pupil with autism, and that the staff members need to learn about autism. All believe that inclusion is a long process that needs to be improved.

\title{
5. CONCLuSion
}

This study focused on EFL teachers who include kids with special needs in a regular-education school. The study aimed to locate central themes regarding the attitudes of the staff towards inclusion of kids with autism in the regular English classroom, and to come up with possible differences in attitudes towards inclusion between the teachers, who took part in the interviews.

\subsection{Attitudes Towards Inclusion}

Successful inclusion of students with Autism Spectrum Disorder (ASD) in general education classrooms is challenging and thus requires additional support (Cross land \& Dunlap, 2012). Positive attitudes are expressed by the EFL teachers, who took part in this study, regarding inclusion. However, these feelings are not enough to guarantee successful inclusion, as all teachers participated in this study, mention the need for urgent support and professional guidance to perform the inclusion task efficiently. The EFL teachers who are trained to teach regular kids, lack formal knowledge of autism. Most of the knowledge, the teachers talked about in their interviews, comes from the field, and not as a result of organized information being passes on to them. Specifically, the teachers spoke about behavioral problems of the kids with autism and discussed the differences between a pupil with autism and a regular pupil. They explained that pupils with autism say what is on their mind, as their emotional aspect is different, and they need routine (Ben-Tzvi, 2009; American Psychiatric Association, 2013). Specifically, if there is a change in the daily routine, it must be explained to the autistic pupils in advance, in order to make it easier on them. Except for one teacher, none of the other staff members are familiar with this important information. Ironically, the teachers in today's situation are expected to properly integrate kids with special needs in their regular education classes, as they are neither provided with sufficient knowledge, appropriate support nor constant guidance.

The English teachers request more assistance of additional personnel (McNally, Cole, Waugh, 2001). For example, through the interviews, English teachers reported that the autistic pupils have much difficulty in something so simple like choosing a pencil, and putting it down when the teacher asks to do so. This difficulty wastes the time of learning and the advancing in the regular English lesson, and may negatively affect inclusion, as many times, the teacher had to warn the pupils with autism.

Even though there are difficulties with inclusion, the whole staff expresses strengths, as all want the pupils to succeed and make a point in saying that they really try their best to make it happen. Some teachers are really determined to help all their pupils succeed, even though they all feel they lack the skills and strategies to deal with inclusion (Padmadewi, Artini 2017). Helping each other to succeed is a strong theme found throughout the interviews. Even though there is a big circle of help, that is in action, in order for the inclusion of autistic pupils in a regular English class be successful, the teacher and assistant need get professional guidance how to work closer together and implement co-teaching (Padmadewi \& Artini, 2017). The buddy program, in which regular pupils naturally help the autistic 
pupils in different ways (Shavit \& Tal, 2013) is also viewed as successful according to the English teachers. This program builds the confidence of the pupil with autism, in specifically defined situations, and also contributes to the regular pupil, who motivates the pupil with autism in all aspects. It is therefore a win-win situation for both sides (Ferraioli \& Harris, 2011)

The achievements described are the result of knowledge and experience in teaching and good intuition and thinking, flexibility and thinking out of the box. However, these are insufficient, as the EFL teachers do not have enough confidence in their actions, and feel helpless or overloaded, at times. We found the theme of self -reduction to be very important, as the feelings of helplessness deserve urgent treatment and special attention to prevent frustration, negative feelings and emotions from the teachers.

These findings are essential, as inclusion in schools today is a very important topic that is relevant to all staff members. More and more schools and preschools have opened up to include pupils with special needs (Boujut, et al, 2016; Dromi, 2018). Specifically, the multiple roles of educators to young children are crucial, as they work with the diverse needs of children with autism in their classrooms (Vakil, Welton, O'Connor \& Kline, 2009). Hence, special attention and essential changes are required from the board of education to make inclusion possible and effective to all parties (Balas \&Adler, 2004).

\subsection{Differences in Attitudes}

Contrary to previous studies that showed that regular-education- teachers hold less favorable attitudes towards inclusion (Cassady, 2011; McNally, Cole, Waugh, 2001), the current study generally revealed positive attitudes towards inclusion. We found through the interviews held, that even though there are many difficulties of the staff members, most of the staff is for inclusion of pupils with autism in the regular EFL classes, if support and guidance are given. They also discuss the benefits of inclusion EFL classrooms for students with Autism Spectrum Disorders, as acknowledge in previous studies (Meindl, Delgado \& Casey, 2020).

The English teachers who took part in this study want to include kids with autism; however, they lack knowledge on the topic (Padmadewi, Artini 2017). These findings clearly indicate that without proper tools and massive support for teachers, inclusion will fail. For example, we found a few negative cases, that need to be taken into account, as the English teacher mentioned a situation, where the pupil with autism went ballistic on a stormy day, as he could not bared the scary sounds of the storm and the English lesson was a disaster. The English teacher was stressed and felt helpless. Situations like this are hard to forget, and again indicate that professional assistance is requested.

Finally, Autism has gained relevance in the last decade (Dromi, 2018) and the topic of inclusion of pupils with autism is evolving and developing quickly. This study highlights the need to help teachers who include kids with autism in their regular EFL classes, together with other kids with various difficulties. The teachers who are motivated to integrate feel helpless, due to lack of knowledge and emotional support. The study indicates the impossible situation in which the educational system increases inclusion of kids with special needs in regular education classes. However, it does not provide teachers with sufficient knowledge to cope with this challenge. The results show how important it is to assist these teachers. Massive knowledge about autism and inclusion should be an integrated part of teacher training and follow the ongoing educational work. Teachers' confidence in their knowledge and abilities will hopefully lead to an optimal process of inclusion, whereas poor knowledge may arouse burnout and feelings of frustration by the teachers, that will severely affect the success of inclusion.

\section{REFERENCES}

[1] Alfi-Shabtay, I. \& Hemed-Kotka, K. (2021). Experienced Second-Career English Teachers: Perceptions towards Professional Change.International Journal on Studies in English Language and Literature (IJSELL), 9(4), 27-38.

[2] American Psychiatric Association. (2013). Diagnostic and Statistics Manual of Mental Disorder (5th Edition). Washington, DC: Author.

[3] Armstrong, F. (2011). Inclusive Education: School Cultures, Teaching and Learning. In Armstrong, F., Richards G. (Ed.), Teaching and Learning in Diverse and Inclusive Classrooms (pp. 7-18). New York: Routledge. 
Perceptions and Attitudes of EFL teachers towards Inclusion of Kids with Autism in the English Classrooms

[4] Avisar, G. (2015). The Essence of Special Education.In A. Alishev- Berski (Ed.), Issues in Special education. Ra'anana: The Open University. [Hebrew]

[5] Avisar, G. \& Almog, A. (2003). Teachers' Training in an Inclusive Era - Where Were We and Where Are We Heading? Issues in Special Education \& Rehabilitation,18 (1), 5-18.[Hebrew]

[6] Ben-Yehuda, S. and Lest, Y. (2004). Attitudes of Teachers Who Succeed in the Social Integration of Students with Special Needs in a Regular Classroom. Issues in Special Education and Rehabilitation, 19 (2), 65-78.[Hebrew]

[7] Balas, N. and Adler, H. (2004). Politics, Education, and Scientific Knowledge - Is There a Connection Between Them? Trends, 1, 1-18.[Hebrew]

[8] Ben-Zvi, M. (2009). Autism treatment through Applied Behavioral Analysis. Kiryat Bialik: Ah, Ltd.[Hebrew]

[9] Boujut, E., Dean, A., Groudelle, A., Cappe, E., (2016). Comparative Study of Teachers in Regular Schools and Teachers in Specialized Schools in France, Working with Students with an Autism spectrum Disorder: Stress, Social Support, Coping Strategies and Burnouts. Journal of Autism \& Developmental Disorders, 46: 2874-2889.

[10] Bowen, A. G. (2006). Grounded theory and sensitizing concepts. International Journal of Qualitative methods, 5(3), 1-12.

[11] Bugdashina, A. (2003). Issues of sensory perception in autism and Asperger syndrome. Kiryat Bialik: "Ah" Ltd. [Hebrew]

[12] Cassady, J. M. (2011). Teachers' attitudes towards the inclusion of students with autism and emotional behavioral disorder. Electronic Journal for Inclusive Education, 2 (7), 5-13.

[13] Creswell, J. W. (2013). Qualitative inquiry and research design: Choosing among five approaches $\left(3^{\text {rd }}\right.$ ed.). Thousand Oaks, CA: Sage.

[14] Dromi, A. (2018). Autism A Journey to Understanding the Continuum. Israel: Books Niv Publishing House. Implementation of the "Integration Law" - updated document Vergen, 2007 (25-51). [Hebrew]

[15] Dushnik, L., \& Sabar Ben-Yehoshua, N. (2001). Ethics of qualitative research. In N. Sabar-Ben Yehoshua (Ed.), Genres and tradition in qualitative research (pp. 343-368). Ganei-Aviv-Lod, Israel: Dvir. [Hebrew].

[16] Dyson A., Jones L., Kerr K., (2011). Inclusive Education. Cambridge, Massachusetts: Harvard Education Press.

[17] Egel, K., Meleechi, S. (2007). The law of Special Education- A social, ethical and professional reflection on policy design and implementation. In S. Reiter, Y. Lazer and G. Avisar (Ed.), Combinations: Students with Disabilities in the Education System (pp. 89-142). Haifa: "Oha".[Hebrew].

[18] Ferraioli, S. J. \& Harris, S. L. (2011). Effective educational inclusion of students on the autism spectrum. Journal of Contemporary Psychotherapy, 41 (1), 19-28.

[19] Frith, A. (1997). Autism - The Meaning of the Unit. Tel Aviv: Sifriat Poalim. [Hebrew].

[20] Gavish, B. and Shimoni, S. (2006). Teachers' perceptions of integrating students with special needs in their classes. Issues in Special Education and Rehabilitation, 21 (1), 35-54. [Hebrew].

[21] Gibton, D. (2001). Grounded theory: The significant of data analysis processes and theory construction in qualitative research. In N. Sabar-Ben Yehoshua (Ed.), Genres and tradition in qualitative research (pp. 195-228). Ganei-Aviv-Lod, Israel: Dvir. [Hebrew].

[22] Mazza, M., Mariano, M., Peretti, S., Masedu, F., Pino, M., Valenti, M., (2017). The Role of Theory of Mind on Social Information Processing in Children with Autism Spectrum Disorders: A Mediation Analysis. Journal of Autism \& Developmental Disorders, 47,1369-1379.

[23] McNally, R., Cole, P., Waugh, R., (2001). Regular Teachers' Attitudes to the Need for Additional Classroom Support for the Inclusion of Students with Intellectual Disability. Journal of Intellectual \& Developmental Disability, 26, 257-273.

[24] Meindl, J. N. Delgado, D. Casey, L. B. (2020). Increasing engagement in students with autism in inclusion classrooms. Children and Youth Services Review, 111, 104-154.

[25] Mesibov, G. B. \& Shea, V. (1996). Full inclusion and students with autism. Journal od Autism and developmental Disorders, 26 (3), 337-346.

[26] Padmadewi, N. N., Artini, L. P., (2017). Teaching English to a Student with Autism Spectrum Disorder in Regular Classroom in Indonesia. International Journal of Instruction, 10(3), 159-176.

[27] Pedreno, C., Pousa, E., Navarro, J. B., Pamias, M., Obiols, J. E., (2017). Exploring the Components of Advanced Theory of Mind in Autism Spectrum Disorder. Journal of Autism \& Developmental Disorders, 47, 2401-2409. 
Perceptions and Attitudes of EFL teachers towards Inclusion of Kids with Autism in the English Classrooms

[28] Reiter, S. and Sheynin M. (2006). From Integration to Inclusion: A Process of Systemic and Ideological Change in the Treatment Center in TiratHacarmel following the Implementation of the Special Education Law. Issues in Special Education and Rehabilitation,21 (2), 60-72. [Hebrew]

[29] Segall, M. J., Campbell, J. M., (2012). Factors Relating to Educational Professionals' Classroom Practices for the Inclusion of Students with Autism Spectrum Disorders. Research in Autism Spectrum Disorders, 6,1156-1167.

[30] Shani, M. and Regev, H. (2017). Equal Opportunities in Learning: Learning Based on Mathematical Discourse Promotes Understanding for Students on the Autistic Continuum. In S. Reiter, I. Kupferberg, Y. Gilat (Eds.), Contemporary Issues in the Integration of Children and Adults with Special Needs in Israel (pp. 217-213). Tel Aviv: The Mofet Institute. [Hebrew]

[31] Shavit, P. and Tal, D. (2013). Teaching in class combines: current approaches and directions. In S. Avidar (Ed), Combinations (pp. 131-153). Haifa: Offset Carmel Haifa.[Hebrew]

[32] Shkedi, A. (2007). Words That Try to Touch - Qualitative Research - Theory and Application. Tel Aviv: Ramot.

[33] Vakil, S. Welton, E., O’Connor, B., \& Kline, K. S. (2009). Errly Childhood Education Journal, 36 (4), 321-326.

\section{AUTHORS' BIOGRAPHY}
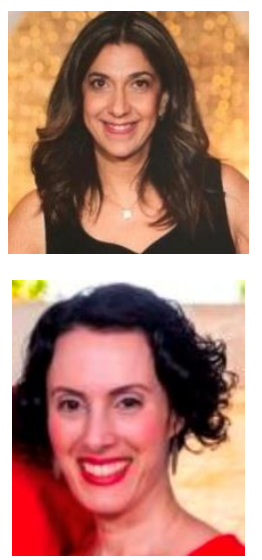

Iris Alfi-Shabtay, $\mathrm{PhD}$, is a Senior Lecturer at the Levinsky College of Education. Her research interests are second language acquisition and bilingualism, foreign language instruction, language assessment and intervention, and EFL instruction. Her research has appeared in books and journals in Israel and worldwide.

Iris Bendavid, is an English teacher [EFL] for Hebrew-speaking students. She is an English coordinator and a school-based teacher educator of English teacher-trainees. M.Ed in Multilingual Education [English], Levinsky College of Education.

Citation: Iris Alfi-Shabtay, Iris Bendavid. "Perceptions and Attitudes of EFL teachers towards Inclusion of Kids with Autism in the English Classrooms" International Journal on Studies in English Language and Literature (IJSELL), vol 9, no. 9, 2021, pp. 69-81. doi: https://doi.org/10.20431/2347-3134.0909007.

Copyright: (C) 2021 Authors. This is an open-access article distributed under the terms of the Creative Commons Attribution License, which permits unrestricted use, distribution, and reproduction in any medium, provided the original author and source are credited. 